\title{
Assessment of Hypertensive Patients' Illness Experience Using Patient-centred Consultation among Patients Seen in an Urban Family-practice Setting in Nigeria
}

\author{
Promise E. Adat ${ }^{1}$, Ndifreke E. Udonwa ${ }^{1,2, *}$, Abraham N. Gyuse ${ }^{1,2}$, Chibuike M. Okeke ${ }^{1}$ \\ ${ }^{1}$ Department of Family Medicine, University of Calabar Teaching Hospital, Nigeria \\ ${ }^{2}$ Department of Family Medicine, Faculty of Medicine, College of Medical Sciences, University of Calabar, Nigeria
}

Copyright $\bigcirc 2017$ by authors, all rights reserved. Authors agree that this article remains permanently open access under the terms of the Creative Commons Attribution License 4.0 International License

\begin{abstract}
Objectives: The study aimed at determining the hypertensive patients' illness experience, using the patient-centred consultation approach in order to form a better partnership with the patients. Design: This was a cross-sectional hospital-based study using a semi-structured questionnaire that assessed the socio-demographic characteristics of the respondents. The respondents' fears about hypertension, ideas about its cause and expectations from consultation were explored. The response was based on a Likert scale. The data were analysed with the SPSS software version 15 . Settings: This study was conducted at the GOPC, UCTH Calabar. The GOPC is the "window" of the Hospital. Subjects/participants: Two hundred and sixty eight hypertensive patients were recruited into the study. Results and Conclusions: The respondents expressed fear regarding most aspect of hypertension. Most (74.7\%) agreed that hypertension could be caused by stress. A few participants gave non-biomedical views of the aetiology of hypertension, including attributing it to spiritual forces. Over three quarters of respondents $(85.1 \%)$, expected their medications to give them corrective measures to hypertension. The study supports the fact that hypertensive patients have varying illness experiences that should be explored using the patient-centred consultation style and recommends that doctors should manage individual patients to suit the patients' unique experience. There was an established significant relationship between expectation and fears/ideas.
\end{abstract}

Keywords Patient-centred Consultation, Hypertensive Patients, Illness Experience

\section{Introduction}

Hypertension, a leading risk factor for mortality worldwide is rising globally as a consequence of urbanization, changing lifestyle patterns and stress. [1] In sub-Saharan Africa, its increase, particularly in the urban region, is due to transition to western lifestyle. [2] In Nigeria, it is the number one risk factor for stroke, heart failure, ischaemic heart disease, and kidney failure. With increasing adult population as well as rising prevalence of hypertension, Nigeria may experience economic and health challenges due to the disease if the tide is not arrested. [1]

The increase in the proportion of hypertensive patients justifies efforts towards early detection of this disease with appropriate treatment and adherence to treatment so as to have a favorable impact on the control of hypertension. This will help to reduce the burden of the disease on the patient, his family and the healthcare system.

One of the strategies to improve adherence to antihypertensive therapy depends on understanding the illness perspective of hypertensive patients using the patient-centred consultation approach during consultation. [3] This would affect the outcome of the patients' illness, treatment, vulnerabilities to complications, management and compliance, and personal satisfaction. [4]

Patient-centred care implies individualized patient care based on patient's specific information rather than focusing exclusively on the disease. This creates a comprehensive approach to health care that is responsive to the patient's needs and preference while ensuring that the patient is treated in a dignified and supportive manner. [5] The concept is not new but its value has been overlooked in preference for technology-centred, doctor-based and diseases-based model of care which has prevailed in the past. [5] The concept incorporates all needs of the patient including medical, financial, psychological and spiritual needs. [6] It requires that the highest level of evidence is used to guide the patient when appropriate in making a well-informed decision and be fully involved in the management of their conditions thus balancing the patients' preference with sound clinical practices. The approach is compassionate, convenient, safe, 
cost-effective and efficient. The patient-centred concept is a holistic approach of care and a major attribute of the bio-psychosocial model of care integrating psychosocial factors into the consultation in order to achieve a fuller understanding of the illness while guiding treatment choices and paying close attention to health promotion. [7] This will enable the physician to provide management interventions of hypertension based on the individual patients' experiences. This model of care has proved to be advantageous in a number of areas including the patient's health, the patient's and physician's satisfaction and practice management. [5]

\section{Materials and Method}

The study was a hospital-based cross-sectional analytical study conducted at the General Out-patient Clinic (GOPC) of University of Calabar Teaching Hospital (UCTH), Calabar. It covered four months from September 2011 to December 2011. The GOPC is one of the entry points of the Hospital that offers primary care services to all patients.

Hypertensive patients from 18 years and above, who gave written informed consents and had been on antihypertensive medication for at least six months, were included in the study. Critically ill patients were excluded from the study.

Using convenient sampling technique, every consecutive patient who met the study inclusion criteria was assured of their confidentiality and included in the study until the sample size of 268 was reached. Information was obtained from a physician-conducted (researchers) patient- centered consultation during each clinic visit.

The data were collected via a researcher-administered semi-structured questionnaire, which was developed by the researchers to elicit socio-demographics and patients' illness experience. It was developed after careful literature review on the bio-psycho-social model of care that seeks to expose the patients' understanding of the disease and their illness experiences. It was divided into four sections that assessed the socio-demographic characteristics of the respondents, fears, ideas, and expectations respectively. Response option was based on a 3-point Likert-like scale that ranged from don't know, agrees to disagree. The questionnaire was pretested in a group of hypertensive patients with similar socio-demographic characteristics.

The data entry was analyzed using the Statistical Package for Social Sciences (SPSS Inc. Chicago, IL) version 18. Variables were analyzed with descriptive statistics, showing the frequencies and percentages. Bi-variate analyses amongst the facets of illness experience were done with chi square statistic. All p-values less than 0.05 were considered statistically significant.

Approval for the study was obtained from the Research and Ethics Committee of the UCTH, Calabar.

\section{Result}

Table 1 illustrates that one hundred and sixty five study respondents were females while 103 were males. All the respondents were between the ages of 20 and 65 years with most (91) of them falling between the age of 50 and 59 years. Married patients were more than single patients in this study. Almost all the patients were Christians while a few were Muslims. Most of the study participants (233) had some form of education; only 35 had no education; the Ibibios were more in the study while Efut was the least represented in the study. Other tribes seen in the study included Igbo, Yoruba and Hausa.

Table 1. Socio-demographic characteristics of the patients studied. N=268

\begin{tabular}{|c|c|c|c|}
\hline \multicolumn{2}{|c|}{ Variables } & $\begin{array}{c}\text { Frequency } \\
n=268\end{array}$ & $\begin{array}{c}\text { Percentage } \\
(\%)\end{array}$ \\
\hline \multirow{5}{*}{ Age (Years) } & $20-29$ & 12 & 4.5 \\
\hline & $30-39$ & 35 & 13.0 \\
\hline & $40-49$ & 71 & 26.5 \\
\hline & $50-59$ & 91 & 34.0 \\
\hline & 60 and above & 59 & 22.0 \\
\hline \multicolumn{4}{|l|}{ Sex } \\
\hline & Male & 103 & 38.4 \\
\hline & Female & 165 & 61.6 \\
\hline \multicolumn{4}{|l|}{ Marital status } \\
\hline & Single & 17 & 6.3 \\
\hline & Married & 182 & 67.7 \\
\hline & Divorced & 6 & 2.2 \\
\hline & Separated & 8 & 3.0 \\
\hline & Widowed & 55 & 20.5 \\
\hline \multicolumn{4}{|l|}{ Religion } \\
\hline & Christianity & 260 & 97 \\
\hline & Islam & 8 & 3 \\
\hline \multicolumn{4}{|l|}{ Occupation } \\
\hline & Civil service & 104 & 38.8 \\
\hline & Trading & 68 & 25.4 \\
\hline & Farming & 28 & 10.5 \\
\hline & Schooling & 14 & 5.2 \\
\hline & Unemployed & 10 & 3.7 \\
\hline & Artisans & 20 & 7.5 \\
\hline & Retired & 24 & 8.9 \\
\hline \multirow[t]{5}{*}{ Education } & None & 35 & 13.1 \\
\hline & Primary & 63 & 23.5 \\
\hline & Secondary & 83 & 31.0 \\
\hline & Tertiary & 77 & 28.7 \\
\hline & Others & 10 & 3.7 \\
\hline \multirow[t]{6}{*}{ Tribe } & Efik & 80 & 29.9 \\
\hline & Qua & 5 & 1.9 \\
\hline & Efut & 4 & 1.5 \\
\hline & Ibibio & 87 & 32.5 \\
\hline & Annang & 13 & 4.9 \\
\hline & Others & 79 & 29.3 \\
\hline
\end{tabular}

From figure 1 below, 160 patients agreed that they feared death from hypertension, while the rest (108) either 
disagreed or did not know if they feared death from hypertension.

One hundred and eighteen patients were afraid of side effects of their medication, 124 disagreed to this while 26 patients did not know if they were afraid of side effects of their medications.

About half of the patients (154) feared the complication of hypertension, 81 patients did not have fear of complication of hypertension, and 33 patients did not know if they feared the complication of hypertension.

One hundred and forty patients agreed that they had fear of lifetime use of medication, 112 patients disagreed to this while 16 patients did not know if they were afraid of long term use of their medication.

One hundred and six patients had fear of making lifestyle changes, 27 patients did not know if they were afraid of making lifestyle changes while 135 patients disagreed to fear of making lifestyle change

Table 2 shows specific reasons for fear of hypertension and its management. Among those who were afraid of death, 84 and 31 participants were afraid because of death of a family member and death of a friend respectively. Forty-five participants were afraid of death from hypertension because of media information that hypertension kills.

Headache was the most (46) frequently mentioned side effects feared by respondents in this study, this was followed by dizziness. A few patients (22) mentioned other side effects including cough and frequent urination.

Similarly, stroke was the most common complication feared by the study participant (55) followed by heart failure (46). Other respondents mentioned erectile dysfunction and heart attack.

Concerning long term use of medication, 47 patients were afraid of life-time dependence on medications. A few (45, 27) attributed their fear to cost and side effects of medication respectively. Other participant also feared the influence of drugs on their social life.

Among the lifestyle changes participant were afraid of making, most (40 participants) feared making dietary changes.

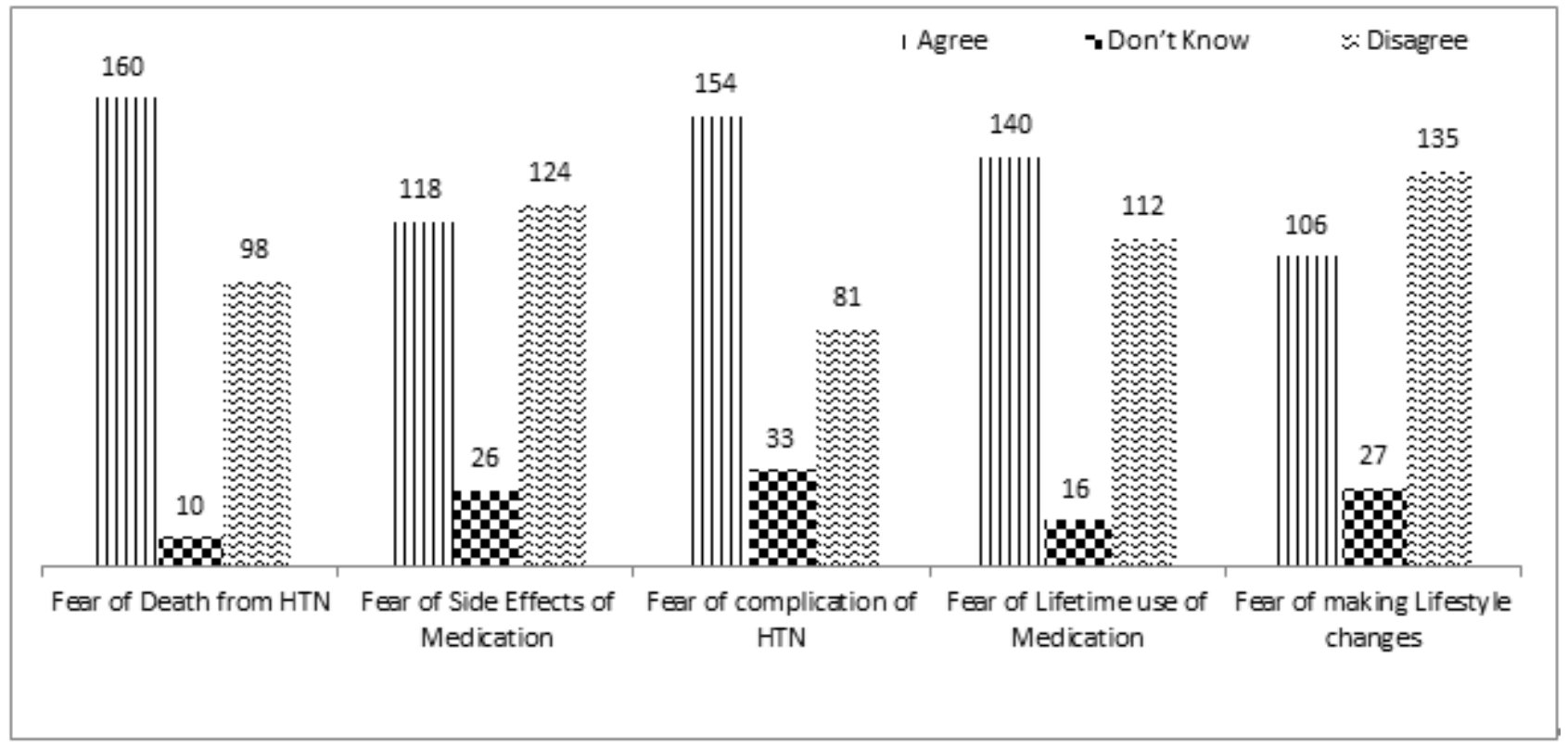

Figure 1. Pattern of response to fear of hypertension, its management and complication in the study population 
Table 2. Pattern and reasons for fear by hypertensive patients in the study

\begin{tabular}{|c|c|c|c|}
\hline Variables & & Frequency $(n=268)$ & Percentage $(\%)$ \\
\hline \multicolumn{4}{|c|}{ Fear of death from HTN } \\
\hline & Death of a family member & 84 & 31.3 \\
\hline & Death of a friend & 31 & 11.6 \\
\hline & Others & 45 & 16.8 \\
\hline & Total & 160 & 59.7 \\
\hline \multicolumn{4}{|c|}{ Types of side effects Feared by hypertensive patient } \\
\hline & Headache & 46 & 17.2 \\
\hline & Dizziness & 29 & 10.8 \\
\hline & Nausea & 11 & 4.1 \\
\hline & Vomiting & 10 & 3.7 \\
\hline & Others & 22 & 8.2 \\
\hline & Total & 118 & 44.0 \\
\hline \multicolumn{4}{|c|}{ Complication feared by hypertensive patients } \\
\hline & Kidney failure & 27 & 10.1 \\
\hline & Heart failure & 46 & 17.2 \\
\hline & Stroke & 55 & 20.5 \\
\hline & Eye problem & 17 & 6.3 \\
\hline & Others & 9 & 3.4 \\
\hline & Total & 154 & 57.5 \\
\hline \multicolumn{4}{|c|}{ Reason for fear of long term use of medication } \\
\hline & Cost of drugs & 45 & 16.8 \\
\hline & Side effects of drugs & 27 & 10.1 \\
\hline & Dependence on medication & 47 & 17.5 \\
\hline & Others & 21 & 7.8 \\
\hline & Total & 140 & 52.2 \\
\hline \multicolumn{4}{|c|}{ Specific fears of lifestyle changes } \\
\hline & Dietary & 40 & 14.9 \\
\hline & Exercising & 20 & 7.5 \\
\hline & Reduction of alcoholic intake & 38 & 14.2 \\
\hline & Stopping tobacco use & 8 & 3 \\
\hline & Total & 106 & 39.6 \\
\hline
\end{tabular}

From figure 2 below, 200 patients agreed that stress can cause hypertension, 43 patients did not know if stress can cause hypertension while 25 patients disagreed to this.

Some patients (127) agreed that hypertension can be caused by eating certain food, 93 patients did not know if food can cause hypertension, while 48 patients disagreed that food can cause hypertension.

Figure 2 also shows that 111 patients agreed that alcohol ingestion can cause hypertension, 51 patients disagreed to this; 106 patients did not know if alcohol can cause hypertension.

One hundred study participants agreed that hypertension can be caused by spiritual forces, 83 patients did not know if spiritual forces can cause hypertension, while 85 patients disagreed to this.

Fifty-five patients agreed that hypertension can be inherited, 125 patients did not know if hypertension can be inherited, while 88 patients did not agree with this. 


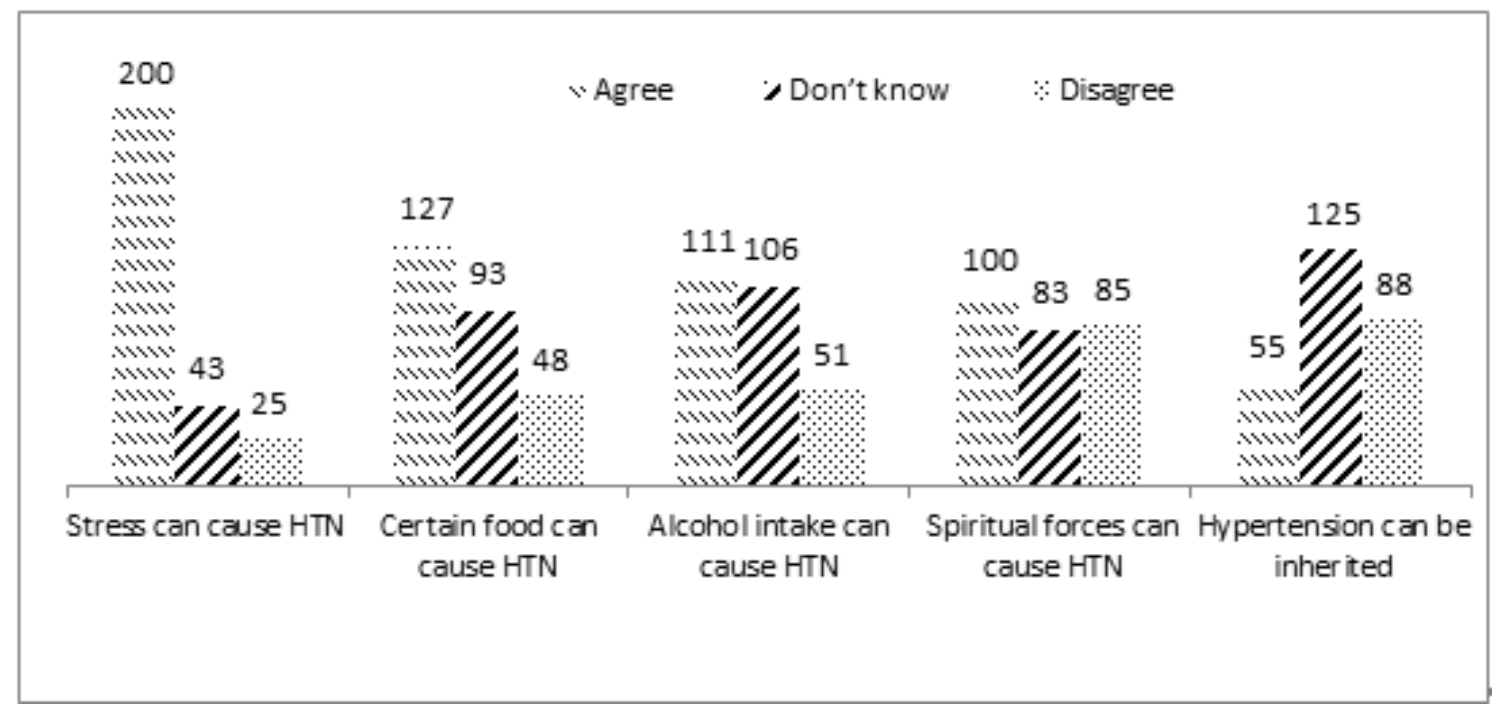

Figure 2. Causes of hypertension

Table 3. Patient of response to specific ideas about the cause of hypertension in the study

\begin{tabular}{|c|c|c|c|}
\hline Variables & & Frequency (n) & Percentage $(\%)$ \\
\hline \multicolumn{4}{|c|}{ Specific stress that can cause hypertension } \\
\hline & Smoking stress & 31 & 11.6 \\
\hline & Work related stress & 43 & 16.1 \\
\hline & Family stress & 76 & 28.4 \\
\hline & Financial stress & 41 & 15.3 \\
\hline & Others & 9 & 3.3 \\
\hline & Total & 200 & 74.6 \\
\hline \multicolumn{4}{|c|}{ Specific food that can cause hypertension } \\
\hline & Red meat & 51 & 19 \\
\hline & Salty food & 36 & 13.4 \\
\hline & Oily food & 24 & 8.9 \\
\hline & Others (Sugary food, Garri) & 16 & 6 \\
\hline & Total & 127 & 47.4 \\
\hline \multicolumn{4}{|c|}{ Specific alcohol that can cause hypertension } \\
\hline & Beer & 19 & 7.1 \\
\hline & Palm wine & 13 & 4.9 \\
\hline & Local gin & 66 & 24.6 \\
\hline & Others & 13 & 4.9 \\
\hline & Total & 111 & 41.4 \\
\hline \multicolumn{4}{|c|}{ Specific spiritual force that can cause hypertension } \\
\hline & Demonic & 29 & 10.8 \\
\hline & Witch craft & 60 & 22.4 \\
\hline & $\begin{array}{l}\text { Others (Spiritual } \\
\text { poisoning) }\end{array}$ & 11 & 4.1 \\
\hline & Total & 100 & 37.3 \\
\hline
\end{tabular}


Table 3 shows patients' specific ideas about the cause of hypertension. The most frequently mentioned stress by the participants (76) was family-related stress. Other types of stress mentioned included academic stress and the stress of daily living.

Some patients mentioned certain food as a cause of hypertension. Among them 51, mentioned red meat, 36 mentioned salty foods, 24 mentioned oily foods and others mentioned some food including sugary food.

Sixty-six patients mentioned local gin as the cause of hypertension. Other opined that beer, and palm wine was the causes.

The patients in this study also attributed hypertension etiology to spiritual forces. Some attributed it to witcheraft and demonic forces $(60,29)$. Others (11) mentioned spiritual poisoning.

The figure below shows that 228 respondent agreed that they expected to be educated about hypertension, 19 patients did not agree to this, 21 patients did not know if they wanted education about hypertension. Similarly, 237 agreed that they expected to be offered corrective measures for hypertension; a few patients $(11,16)$ either disagreed or did not know if they wanted corrective measures for their hypertension respectively.
Among those who had indicated that they expected to be educated about hypertension, 74 and 38 patients expected educations about the cause and the duration of illness respectively. Others wanted to be educated about the prognosis of the illness, prevention of their illness and the lifestyle changes to make.

Table 5 shows the relationships between expectation of being educated on hypertension and fears of death from hypertension and two ideas that hypertension is caused by certain foods and by alcohol.

More than three quarter $(138 ; 86.2 \%)$ of respondents who were afraid of death from hypertension, some $(116 ; 91.3 \%)$ of the respondents who were of the idea that hypertension is caused by certain foods, and more than half of the respondents $(74 ; 66.7 \%)$ who believed that hypertension is caused by alcohol; agreed that they expected to be educated on hypertension.

The expectation for education on hypertension was significantly related to the idea that hypertension can be caused by taking certain foods and alcohol ingestion. No significant relationship was found between fear of death from hypertension and expectation of education on hypertension.
228

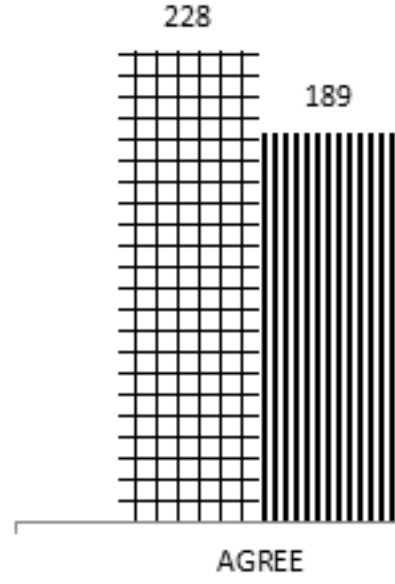

T EXPECTATION OF EDUCATION ABOUT HYPERTENSION

II EXPECTATION OF A CORRECTIVE MEDICATION FOR HYPERTENSION

Figure 4. Expectation of education about hypertension and of corrective medication for hypertension

Table 4. Specific education expected by hypertensive patient

\begin{tabular}{|c|c|c|}
\hline Variables & Frequency (N) & Total (\%) \\
\hline Education about the aetiology of HTN & 74 & 27.6 \\
\hline Education on anti-hypertension medication & 31 & 11.6 \\
\hline Education on the duration of treatment & 21 & 14.8 \\
\hline Education on the duration of illness & 38 & 23.9 \\
\hline Other types of education needed & 64 & 88.1 \\
\hline Total & 228 & \\
\hline
\end{tabular}


Table 5. The relationship between expectation of education on hypertension and fear of death from hypertension, idea that hypertension is caused by certain foods and alcohol intake.

\begin{tabular}{|c|c|c|c|c|c|c|c|}
\hline \multicolumn{2}{|c|}{ Variables } & \multicolumn{3}{|c|}{ Expectation of education on hypertension } & \multirow[t]{2}{*}{ Total } & $\mathbf{X}^{2}$ & p-valve \\
\hline \multirow{4}{*}{$\begin{array}{l}\text { Fear of death } \\
\text { from } \\
\text { hypertension }\end{array}$} & & Agree & I don't know & Disagree & & \multirow{5}{*}{5.50} & \multirow{5}{*}{0.24} \\
\hline & Agree & 138 & 14 & 8 & 160 & & \\
\hline & I don't know & 10 & 0 & 0 & 10 & & \\
\hline & Disagree & 80 & 7 & 11 & 98 & & \\
\hline Total & & 228 & 21 & 19 & 268 & & \\
\hline \multirow{3}{*}{$\begin{array}{l}\text { Hypertension is } \\
\text { caused by certain } \\
\text { foods }\end{array}$} & Agree & 116 & 3 & 8 & 127 & \multirow{4}{*}{30.27} & \multirow{4}{*}{0.00} \\
\hline & I don't know & 83 & 6 & 5 & 94 & & \\
\hline & Disagree & 29 & 12 & 6 & 47 & & \\
\hline Total & & 228 & 21 & 19 & 268 & & \\
\hline \multirow{3}{*}{$\begin{array}{l}\text { Hypertension is } \\
\text { caused by alcohol }\end{array}$} & Agree & 96 & 6 & 9 & 111 & \multirow{4}{*}{14.37} & \multirow{4}{*}{0.006} \\
\hline & I don't know & 96 & 5 & 5 & 106 & & \\
\hline & Disagree & 36 & 10 & 5 & 51 & & \\
\hline Total & & 228 & 21 & 19 & 268 & & \\
\hline
\end{tabular}

Table 6. The relationship between expectation of a corrective medication for hypertension and fear of death from hypertension

\begin{tabular}{|c|c|c|c|c|c|c|c|}
\hline \multicolumn{2}{|c|}{ Variables } & \multicolumn{3}{|c|}{$\begin{array}{c}\text { Expectation of a corrective medication for } \\
\text { hypertension }\end{array}$} & \multirow[t]{2}{*}{ Total } & $X^{2}$ & p-valve \\
\hline \multirow{4}{*}{$\begin{array}{l}\text { Fear of death } \\
\text { from } \\
\text { hypertension }\end{array}$} & & Agree & I don't know & Disagree & & \multirow{5}{*}{10.87} & \multirow{5}{*}{0.028} \\
\hline & Agree & 102 & 33 & 25 & 160 & & \\
\hline & I don't know & 8 & 0 & 2 & 10 & & \\
\hline & Disagree & 79 & 9 & 10 & 98 & & \\
\hline Total & & 189 & 42 & 37 & 268 & & \\
\hline \multirow{3}{*}{$\begin{array}{l}\text { Hypertension is } \\
\text { caused by certain } \\
\text { foods }\end{array}$} & Agree & 83 & 17 & 27 & 127 & \multirow{4}{*}{16.39} & \multirow{4}{*}{0.003} \\
\hline & I don't know & 76 & 15 & 3 & 94 & & \\
\hline & Disagree & 30 & 10 & 7 & 47 & & \\
\hline Total & & 189 & 42 & 37 & 268 & & \\
\hline \multirow{3}{*}{$\begin{array}{l}\text { Hypertension is } \\
\text { caused by alcohol }\end{array}$} & Agree & 74 & 13 & 24 & 111 & \multirow{4}{*}{11.46} & \multirow{4}{*}{0.022} \\
\hline & I don't know & 78 & 18 & 10 & 106 & & \\
\hline & Disagree & 37 & 11 & 3 & 51 & & \\
\hline Total & & 189 & 42 & 37 & 268 & & \\
\hline
\end{tabular}

Table 6 illustrates that $102(63.8 \%)$ of respondents who were afraid of death from hypertension, $83(65.4 \%)$ who believed that hypertension is caused by certain foods, and $74(66.7 \%)$ who believed that hypertension is caused by alcohol, all agreed that they expected to be given corrective medication(s) for hypertension. There was a significant relationship between expectation of corrective medication for hypertension, fear of death from hypertension, the idea that that hypertension could be caused by alcohol intake and certain foods.

\section{Discussion}

In this study all the respondents were between the ages of $20-65$ years with more patients in the age class of 50-59years. This may be explained by the fact that hypertension is more prevalent with advancing age. [9] There were more female hypertensive patients than male in this study. This is likely due to gender differences in seeking medical care because women are more likely to seek health care than males. [10] Most of the participants had some form of formal education while a few did not have any education. The level of education can influence knowledge, beliefs, attribution and practices relating to health and other domains of life. [11]

Close to two thirds of the patients were afraid of death from hypertension. This was in line with the findings of a study carried out in Auchi, Nigeria where a similar fraction of the respondents expressed fear of death from hypertension. The reason for fear of death was explored and it was found that most of the respondents feared death because death of a relative or friend from hypertension. Other reasons offered for fear of death included; 
information from the media and health workers that hypertension could kill. Fear of death is a rational response to a chronic illness that is incurable. It may be due to lack of comprehensive knowledge about the manageable nature of hypertension. This necessitates public enlightenment about adequate and correct information about hypertension. Some patients who either did not know or disagreed that they feared death from hypertension may have said so in order to avoid talking about it, as death is not a topic most people would want to discuss at any time or during consultation.

Almost half of the study participants expressed fears about the side effects of medication while a similar fraction did not fear their medications' side effects. Headache was the commonest side effect feared by the patients while the least feared was vomiting. This is not surprising given the fact that headache is an important side effect of calcium channel blocker a class of antihypertensive drug that is commonly used in the GOPC. Similarly, in Auchi Nigeria, the study participants expressed fear of side effects of medication such as polyuria, headache, sexual dysfunction and oedema. [12] Fear of side effects of medication has an implication on adherence and may also be a reason for patients to seek an alternative source of care.

The commonest complication of hypertension that was feared by the participants was stroke perhaps because in our environment stroke is more easily diagnosed than myocardial infarction. Furthermore, locally stroke is thought to be caused by "a slap from a ghost", this alone will invoke an intense fear in any patient. This was closely followed by fear of heart failure. This result is similar to another study in Greece where the frequently mentioned complications included stroke. [13] Having these fears suggests a degree of knowledge of complications of hypertension and this could serve as an important motivation to adhere to treatment regimen.

Amongst patients with fear of long term use of their medication most were afraid of being dependent on drug. Similar result was obtained in Karachi, Pakistan where some of the hypertensive patients were afraid of being dependent on their medications. [14] Therefore, there is a need for practitioners to create a conviction that antihypertensive drugs should be taken daily and on no account do they pose the threat of dependence. Given the rate of poverty in Nigeria, cost also featured as a reason for fear of long term use of medication likewise side effects of medication though this was the least mentioned by the study participants.

One third of the study respondents were afraid of changes they've been asked to make about their lifestyle; such changes included changes in diet which ranked highest followed by exercise, reduction of alcohol intake and stopping the intake of tobacco. There is paucity of data concerning fear of making lifestyle changes. This was assessed because lifestyle management is an important aspect of hypertension management and every effort should be made to determine the patients' fears or concerns about it.

Most of the patients in this study were of the idea that stress could cause hypertension. In a similar study carried out in South East Amsterdam among individuals from different tribes, three quarters of the Ghanaians, a subset of West African population, were of the idea that stress was the principal cause of hypertension; this was further attributed to social pressures as well as family obligation. [15] Similarly a study carried out in Benin, Nigeria among hypertensive patients showed that slightly above half of the hypertensive patients strongly linked stress to the aetiology of high blood pressure though no specific type of stress was mentioned. [16] Of the various type of stress mentioned in this study, family-related stress rated highest, this was closely followed by work related stress, emotional stress and financial stress. In the study environment, the family is an important unit of existence but may also act as a stressor for an individual. Persistent stress can lead to repeated blood pressure elevation which when sustained can lead to hypertension. The perception that stress is a cause of hypertension is common among patients worldwide irrespective of their tribe. [17]

Close to half of the study participants were of the idea that hypertension could be caused by eating certain foods. Specifically, red meat ranked the highest, followed by salty food, oily foods and others including sugary food. This result was contrary to what was obtained in a study carried out in Auchi, Nigeria where all the study participant affirmed that hypertension could not be cause by taking foods such as many commercially available additives or condiments with high salt component.[12] In an aforementioned study with participants from different ethnic groups, the Ghanaians were of the idea that eating starchy food and undercooked red meat could cause hypertension while the Surinamese and Dutch respondent were of the idea that salty diet and liquorices were the main cause of hypertension respectively. [16] In Benin, Nigeria, a quarter of the patients in a hypertensive study attributed the aetiology of hypertension to salt intake. [15] This implies that salt is thought to cause hypertension in many cultures.

About two-thirds of the study participants mentioned alcohol ingestion as an aetiology of hypertension. Specifically locally brewed gin ranked the highest as a cause of hypertension followed by beer and palm wine. However, in a study carried out in South East Amsterdam beer featured prominently as a cause of hypertension.[16] Alcohol is not a direct cause of hypertension however excessive drinking can lead to an increased risk of hypertension. Local gin was included in this study because it is locally made and is readily available for consumption in and around Cross River State, likewise palms wine.

Over one third of the patients were of the opinion that spiritual force can cause hypertension, mainly, witcheraft was mentioned. It is comparable to the findings of another study carried out in Auchi, Nigeria among hypertensive 
patient where a similar fraction of the study participants also attributed the aetiology of hypertension to spiritual forces. [12] These believe may be due to cultural and religious influences on health leading to Africans attributing the aetiology of diseases to supernatural/spiritual forces. This may decrease the reliance on medication as the patient may be searching falsely for what is responsible for their dilemmas.

Additionally, a quarter of the patients attributed the cause of hypertension to the fact that it could be inherited. This was lower than what was obtained in Auchi, Nigeria, where over half the respondents said it was an inheritable disease. [12] This result shows that there was low level of knowledge about the idea that hypertension can be inherited. The knowledge of hypertension as an inheritable disease has an implication on presentation at a health facility for screening for hypertension in other family members.

A good number of patients required education about hypertension and its management. The type of education required included; education regarding the duration of treatment, duration on medication and cause of the disease. In a study carried out in Pakistan, a similar proportion of hypertensive patients expected their physician to educate them about hypertension and its management. [18]

Despite the well-known fact that hypertension medications are merely used to control blood pressure and reduce the risk of complication, [19] close to three quarters of the study participants expected corrective measures for hypertension. The expectation of a corrective measure for hypertension necessitates that physicians should use the consultation as an opportunity to provide patients with realistic education that will aid their understanding of hypertension and its management.

To the best of the knowledge of the authors, there are no study in the study environment that shows the relationship between fear, ideas and expectations amongst hypertensive patients. The idea that hypertension can be caused by alcohol and certain foods had statistical significant relationship with the expectation for education on the illness. These relationships indicates that though the patients in this study mentioned some possible aetiology for hypertension, there was an innate need to know more about hypertension. The need for the education may also help patients to modify their lifestyles in order to achieve a favorable outcome in management of their illnesses.

There was also a statistical significant relationship between expectation of corrective medication for hypertension, fear of death from hypertension, the idea that hypertension is caused by certain foods and alcohol. Therefore, it may be surmised that fear and certain ideas about the aetiology of hypertension is a strong motivation for seeking to obtain correction for the illness.

\section{Conclusions}

This study supports the fact that hypertensive patients have varying illness experience that can be explored using the patient-centred consultation style. The respondents in this study exhibited fears about every aspect of hypertension and its management. A good number attributed hypertension aetiology to the risk factors for hypertension. The participants had expectation of education about hypertension and its management including expectations of corrective measures for hypertension despite the well-known fact that hypertension can only be managed. Therefore, the illness experience investigated in this study has given an insight into what individual patients are passing through; this would form a basis for which physicians should plan their management to suit the patients' unique situation. Based on the established relationships seen in this study, perhaps assessing the illness experiences of patients may be an important strategy in determining the need for education and this may help to correct the impression that hypertension cannot be completely corrected by medication (except in cases of secondary hypertension) but that it is a chronic illness requiring a lifetime management.

\section{REFERENCES}

[1] O.S Ogah, I. Okpechi, I.I Chukwuonye, J.O Akinyemi, B.J.C Onwubere, A.O Falase et al. Blood pressure, prevalence of hypertension of hypertension and hypertension related complication in Nigeria, Africa. World journal cardiology vol.4 No.12, 327-340, 2012.

[2] M.E Henrick, F.W Wit, L.M Brenster, T.MAkande, H.T de Beeer. Hypertension in Subsaharan Africa; cross-sectional survey in four rural and urban communities. PloS ONE Vol.7 No.3, e32638.

[3] S.L Chen, J.C Tsai, W.L Lee. The impact of illness perception on adherence to therapeutic regimen of patients in Taiwan. J. Clinical NursVol8 No15, 2234-2244, 2009.

[4] F. Alhalaiga, K.H Deane, R. Gray. Hypertensive patients' experience with adherence therapy for enhancing medication compliance: a qualitative exploration. J. ClinNurs, Vol 22, No 13, 2039-2052, 2013.

[5] R. Jayadevappa, S. Chantre. Patient centre care - a conceptual model and review of state of the art. The Open Health Services and Policy Journal, Vol. 4:15-25, 2011.

[6] K. Flynn. Brief overview: systematic review of patient centre care. Accessed from www.va.gov on the $13^{\text {th }}$ of April 2013.

[7] L. Frostholm, E. Oernboel, K.S Christensen, T. Toft, F. Olesen, J. Weinman. The uncertain consultation and patient satisfaction. The impact of patients' illness perceptions and randomized controlled trials on the training of physician's communication skills. Psychosomatic Medicine, Vol. 67 No 6,897-905, 2005.

[8] O. Ekunife, C.N. Aguwa. A meta-analysis of prevalence rate of hypertension in Nigerian population. Journal of Public Health and Epidemiology, Vol. 3, No. 13, 604-607, 2011. 
[9] O.M. Kayode, G.O. Oke. A ten year study of the pharmacotherapy of hypertension at a tertiary Hospital in South Western Nigeria. Asian J. Pharm Clin Res, Vol.5, No.1, 26-29, 2012.

[10] M.K. Muriithi. The determinant of health seeking behavior in a Nairobi slum, Kenya. European Scientific Journal, Vol9, No.8, 1857-7881, 2013.

[11] P.E. Osamor, B.E. Owumi. Factors associated with treatment compliance in hypertensives in South West Nigeria. J. Health Population Natr, Vol. 29, No. 6, 619-628, 2011.

[12] G.B.S. Iyalomhe, S.I. Iyalomhe. Hypertension-related knowledge, attitude and lifestyle practices among hypertensive patients in a Sub-Urban Nigerian Community. Journal of Public Health and Epidemiology, Vol.2, No.4, 71-77, 2010.

[13] V. Tsiantou, P. Pantzou, E. Paoi, G. Koulierakis, J. Kyriopoulus. Factors affecting adherence to antihypertensive medication in Greece: result from a qualitative study. Patient Prefer Adherence, Vol.4, 335-343, 2010.

[14] S.K. Hashmi, M.B. Afridi, K. Abbas, R.A. Sajwani, D.
Saleheen, P.M. Frossard et al. Factors associated with adherence to anti-hypertension treatment in Pakistan: PloS One, Vol.2, No.3, e280, 2007.

[15] E.J. Beune, J.A. Haafkens, J.S. Schuster, P.J. Bindels. Under pressure: how Ghanaians African-Surinamese and Dutch patients explain hypertension. Journal of Human Hypertension, Vol.20, 946-955, 2006.

[16] I.E. Chiazor, A.C. Oparah. Assessment of hypertension cares in a Nigeria hospital. Tropical Journal of Pharmaceutical Research, Vol.11, No.1, 137-145, 2012.

[17] A. King. Hypertension: understanding patients' perception could improve therapy. Nature Reviews Cardiology, Vol.9, p494, 2012.

[18] T. Saleem, U. Khalid, W. Qidwai. Geriatric patients' expectations of their physicians: findings from a tertiary care hospital in Pakistan. BMC Health Serv Res, Vol.9, p205, 2009.

[19] S. Makridakis, J.J Di Nicolantonio. Hypertension: empirical evidence and implications in 2014. Open Heart, Vol.1, e00048, 2014. 